DOI: https://doi.org/10.24867/06BE38Maksimovic

\title{
REGULACIJA TEMPERATURE KGH SISTEMA UPOTREBOM PI-LIKE FUZZY REGULATORA I GA
}

\section{TEMPERATURE REGULATION OF HVAC SYSTEM USING PI-LIKE FUZZY CONTROLLER AND GA}

\section{Saša Maksimović, Fakultet tehničkih nauka, Novi Sad}

\begin{abstract}
Oblast - ELEKTROTEHNIKA I RAČUNARSTVO
Kratak sadržaj - Osnovni zadatak ovog rada jeste regulacija temperature $K G H$ sistema, a da se pri tom ne naruše zahtevani radni uslovi. Korišćen je PI-like fuzzy regulator, koji upravlja ventilom za dovod hladne vode na izmenjivač toplote KGH sistema. Izvršena je optimizacija fuzzy tabele pravila pomoću genetskih algoritama.
\end{abstract}

Ključne reči: PI-like fuzzy regulator, GA, KGH sistemi

\begin{abstract}
The main goal of this paper is the temperature regulation of HVAC system, without influence on the required operating conditions. PI-like fuzzy controller was used, that controls valve for the flow rate of cold water through the heat exchanger of HVAC system. Optimization of fuzzy rules table using genetic algorithms was performed.
\end{abstract}

Keywords: PI-like fuzzy Controller, GA, HVAC system

\section{UVOD}

Sa značajnim porastom potrošnje energije u zgradama, strategije štednje energije postale su prioritet u mnogim državama. Kategorije zgrada i sistemi klimatizacije, grejanja i hlađenja - KGH sistemi su ključni elementi koji utiču na potrošnju energije u zgradama, skoro 50\%. Stoga je razvoj i implementacija efikasnih kontrolnih tehnika KGH sistema od primarnog značaja. Tačnije, sa smanjenom cenom obrade, skladištenja podataka i generalno komunikacija proteklih godina, dizajn i implementacija kompleksnijih upravljačkih tehnika postali su izvodljivi [1].

\section{ENERGETSKA EFIKASNOST}

Pod pojmom unapređenja energetske efikasnosti $u$ zgradarstvu podrazumeva se kontinuirani i širok opseg delatnosti kojima je krajnji cilj smanjenje potrošnje svih vrsta energije uz iste ili bolje uslove u objektu.

Pojam energetska efikasnost najčešće se susreće u dva moguća značenja, od kojih se jedno odnosi na uređaje a drugo na mere i ponašanja. Pod energetski efikasnim uređajem smatra se onaj koji ima veliki stepen korisnog dejstva. Energetska efikasnost u zgradarstvu podrazumeva efikasno korišćenje energije uz primenu optimalnih mera čiji je cilj: smanjenje potrošnje energije uz finansijsku

\section{NAPOMENA:}

Ovaj rad proistekao je iz master rada čiji mentor je bio dr Velimir Čongradac, vanr.prof. uštedu za krajnjeg korisnika, ugodniji i kvalitetniji boravak u zgradi, smanjenje troškova održavanja i produženje životnog veka zgrada, doprinos zaštiti okoline i smanjenju emisija štetnih gasova kao i globalnim klimatskim promenama [2].

\section{KGH SISTEMI}

Sistemi klimatizacije, grejanja i hlađenja (KGH) su osmišljeni da zadovolje zahteve udobnosti ljudi i procesa. Glavna misija KGH sistema je da zadovolji toplotnu udobnost ljudi podešavanjem i promenom spoljašnjih vazdušnih uslova u željene uslove nastanjene zgrade.

Osnovne komponente KGH sistema su: mešaona komora i kontrola spoljašnjeg vazduha, vazdušni filter, ventilator dovodnog vazduha, izduvni ili ventilatori oduška i izlazna grana vazduha, spoljašnji dovod vazduha, kanali za distribuciju vazduha, terminalni uređaji, sistem povratnog vazduha, izmenjivači toplote, samostalna jedinica za grejanje ili hlađenje, rashladni toranj, parni kotao, kontrola, čiler i oprema za vlaženje i odvlaživanje.

Osnovna podela KGH sistema je na centralizovane sisteme i decentralizovane, odnosno lokalne. Tip sistema zavisi od postavljanja lokacije primarne opreme. Koja može biti na jednom mestu, centralizovana, koja će upravljati celom zgradom kao jedinica. Ili decentralizovana, na više lokacija, koja će odvojeno upravljati po zonama zgrade.

Centralizovani KGH sistem može upravljati jednom ili više termalnih zona. Njegova glavna oprema se nalazi izvan zona, na odgovarajućoj centralnoj lokaciji, bilo unutar, na krovu ili pored zgrade. Unutar svake zone potrebne su kontrolne jedinice kao što su termostati [3].

\section{FUZZY LOGIKA}

Fuzzy logika u užem smislu predstavlja viševrednosnu logiku. U klasičnoj, bivalentnoj logici svaki iskaz može biti samo tačan ili netačan. U ljudskom govoru postoji puno iskaza koji nemaju vrednost strogo tačno ili strogo netačno. Da bi se opisali ovakvi iskazi proširena je klasična logika. Tako je nastala fuzzy logika.

U širem smislu fuzzy logika je zapravo teorija fuzzy skupova. Teorija fuzzy skupova je teorija koja proučava objekte kod kojih nije strogo definisana granica pripadnosti nekoj klasi, odnosno objekat pripada određenoj klasi sa nekim stepenom [4]. 
Osnovni element za predstavljanje i obradu nepreciznosti u fuzzy tehnologijama je fuzzy skup. Fuzzy skup predstavlja skup elemenata sa sličnim svojstvima. Dok, diskretan (klasičan) skup predstavlja skup elemenata sa istim svojstvima. U diskretnom skupu svaki element pripada tom skupu sa stepenom pripadnosti jedan. Dok, u fuzzy skupu svaki element pripada tom skupu u izvesnom stepenu [5].

\subsection{Struktura fuzzy regulatora}

Fuzzy regulator se formira kao skup pravila kojima se izražava veza između registrovanih vrednosti na izlazu sistema i upravljanja koje treba da promeni te izlaze, odnosno da ih dovede do željenog ishoda.

Jedina raspoloživa informacija o procesu je realni fizički signal koji je dobijen merenjem. Njegovo korišćenje od strane fuzzy regulatora zahteva da se izvrši fazifikacija tog signala. Konačno i svi trenutno raspoloživi izvršni organi konstruisani su tako da očekuju konkretni fizički signal na svom ulazu, što znači da je neophodno da se na osnovu dobijenog izlaznog fuzzy skupa odredi veličina upravljačkog signala kojim će se pobuditi izvršni organ, odnosno da se izvrši njegova defazifikacija.

Algoritam fuzzy regulatora radi na osnovu specificiranih pravila. Za svaki primljeni izmereni signal algoritam realizuje sledeća tri koraka: fazifikacija ulaznih signala, određivanje fuzzy skupa upravljanja i defazifikacija. Struktura fuzzy regulatora prikazana je na slici 2 [6].

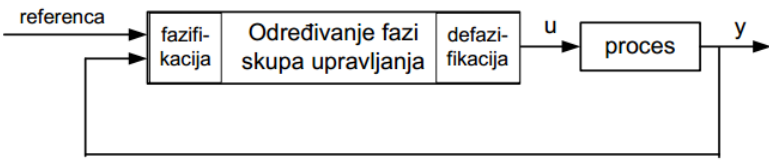

Slika 2. Struktura fuzzy regulatora.

\section{GENETSKI ALGORITMI (GA)}

GA spadaju u grupu stohastičkih optimizacionih metoda koje ne koriste derivacije - izvode funkcija. Bazirani su na konceptu prirodne selekcije i evolucije.

Karakteristike genetskih algoritama: Predstavljaju proceduru paralelnog pretraživanja pogodnu za primenu $\mathrm{u}$ sistemima paralelnog procesiranja. Podjednako su primenljivi u rešavanju kontinualnih i diskretnih optimizacionih problema. Predstavljaju stohastičke metode, manje podložne zapadanju u lokalni minimum. Poseduju veoma velik stepen prilagodljivosti, čime se olakšava njihova primena u okviru problema strukturne parametarske identifikacije složenih modela kao što su neuronske mreže i/ili fuzzy sistemi zaključivanja. Svaku tačku parametarskog ili prostora rešenja predstavljaju preko binarnog niza koji se zove hromozom. Svakom hromozomu je pridružen određen stepen prilagođenosti, tako da se određivanje vrednosti kriterijumske funkcije svodi na procenu njene vrednosti u jednoj tački. Umesto jedne izolovane tačke GA često koriste set tačaka koji se naziva populacija, i koji evoluira u pravcu što boljeg zadovoljenja kriterijumske funkcije. U svakoj generaciji GA primenom genetskih operatora proizvodi novu populaciju. Genetski operatori su selekcija, ukrštanje i mutacija. Članovi populacije koji u većoj meri zadovoljavaju kriterijumsku funkciju imaju veću šansu da prežive i da učestvuju u budućim ukrštanjima. Nakon većeg broja generacija, populacija sadrži članove sa većim stepenom prilagođenja. Često se navode kao primer optimizacije bazirane na populaciji, gde se popravljaju performanse cele populacije, a ne samo određenih jedinki. Osnovni elementi genetskih algoritama su: kodiranje, prilagđenost (stepen pogodnosti), selekcija (odabir roditelja), ukrštanje, mutacija i elitizam [5].

\section{SOFTVERSKO REŠENJE: MODEL VAZDUH - VODA KGH SISTEMA}

U ovom radu korišćen je programski paket Matlab. Zbog nedostupnosti realnog sistema kreiran je simulacioni model pomoću alata Simulink. Pomoću alata FuzzyLogic Toolbox kreirani su PI-like fuzzy regulatori. Optimizacija tabele pravila izvršena je pomoću alata Optimization Tool. Na slici 3 prikazan je simulacioni model vazduh - voda $\mathrm{KGH}$ sistema $\mathrm{u}$ kom se vrši regulacija temperature vazduha upotrebom PI-like fuzzy regulatora [7].

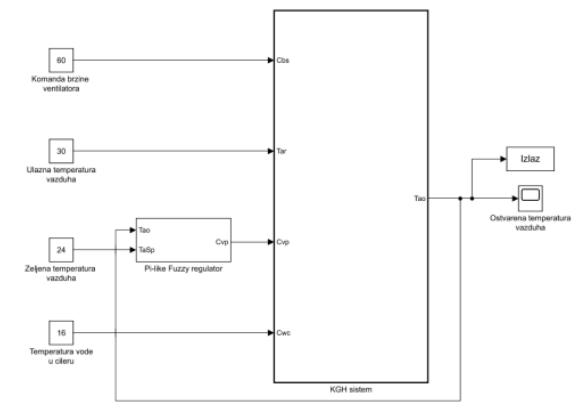

Slika 3. Simulacioni model vazduh - voda KGH sistema.

\subsection{Projektovanje fuzzy regulatora}

Za upravljanje regulacionim ventilom dolazne hladne vode projektovana su dva tipa regulatora, mamdani i sugeno. Napravljeno je nekoliko eksperimenata sa različitim tabelama pravila $(3 \times 3$ i $5 \times 5)$, koje su prikazane u tabelama 1 i 2, respektivno. Cilj je bio poređenje performansi ova dva tipa. Na kraju, urađen je još jedan eksperiment u kom je izvršena optimizacija tabele pravila fuzzy regulatora tipa mamdani $3 \times 3$ pomoću GA.

Za ulazne ( $e-$ greška i $\Delta e-$ izvod greške) i izlazne promenljive (upravljanje) korišćene su funkcije pripadnosti: $N$ - negativno, $Z$ - nula, $P$ - pozitivno, $N B-$ negativno veliki, $N S$ - negativno mali, $P S$ - pozitivno mali i $P B$ - pozitivno veliki.

Tabela 1. Tabela pravila $3 \times 3$.

\begin{tabular}{|c|c|c|c|}
\hline$e^{\Delta e}$ & $N$ & $Z$ & $P$ \\
\hline$N$ & $N B$ & $N S$ & $Z$ \\
\hline$Z$ & $N S$ & $Z$ & $P S$ \\
\hline$P$ & $Z$ & $P S$ & $P B$ \\
\hline
\end{tabular}

Tabela 2. Tabela pravila $5 \times 5$.

\begin{tabular}{|c|c|c|c|c|c|}
\hline$e^{\Delta e}$ & $N B$ & $N S$ & $Z$ & $P S$ & $P B$ \\
\hline$N B$ & $N B$ & $N B$ & $N S$ & $N S$ & $Z$ \\
\hline$N S$ & $N B$ & $N S$ & $N S$ & $Z$ & $P S$ \\
\hline$Z$ & $N S$ & $N S$ & $Z$ & $P S$ & $P S$ \\
\hline$P S$ & $N S$ & $Z$ & $P S$ & $P S$ & $P B$ \\
\hline$P B$ & $Z$ & $P S$ & $P S$ & $P B$ & $P B$ \\
\hline
\end{tabular}




\section{REZULTATI I DISKUSIJA}

Da bi simulacija bila moguća ulazni signali KGH sistema su predefinisani i uneseni kao konstantne vrednosti. U svim ekperimentima korišćeni su identični ulazni signali, da bi se mogle porediti performanse regulatora. Ulazni signali prikazani su u tabeli 3 .

Tabela 3. Vrednosti ulaznih signala KGH sistema.

\begin{tabular}{|c|c|}
\hline Komanda brzine ventilatora $[\%]$ & 60 \\
\hline Ulazna temperatura vazduha $\left[{ }^{\circ} \mathrm{C}\right]$ & 30 \\
\hline Željena temperatura vazduha $\left[{ }^{\circ} \mathrm{C}\right]$ & 24 \\
\hline Temperatura vode u čileru $\left[{ }^{\circ} \mathrm{C}\right]$ & 16 \\
\hline
\end{tabular}

\subsection{Mamdani 3x3}

$\mathrm{U}$ ovom eksperimentu korišćen je mamdani 3x3 fuzzy regulator. Izlazni signal iz $\mathrm{KGH}$ sistema prikazan je na slici 4.

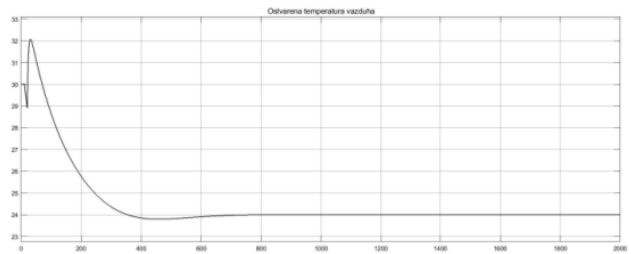

Slika 4. Izlazni signal KGH sistema, mamdani $3 \times 3$. Performanse odziva prikazane su u tabeli 4.

Tabela 4. Performanse odziva KGH sistema, mamdani $3 \times 3$.

\begin{tabular}{|c|c|}
\hline Preskok [\%] & 33,6499 \\
\hline Vreme uspona [s] & 330,0442 \\
\hline Vreme smirenja [s] & 679,2774 \\
\hline Ess - Greška u ustaljenom stanju & $1,8495 \mathrm{e}-05$ \\
\hline
\end{tabular}

\subsection{Sugeno $3 \times 3$}

U ovom eksperimentu korišćen je sugeno 3x3 fuzzy regulator. Izlazni signal iz $\mathrm{KGH}$ sistema prikazan je na slici 5.

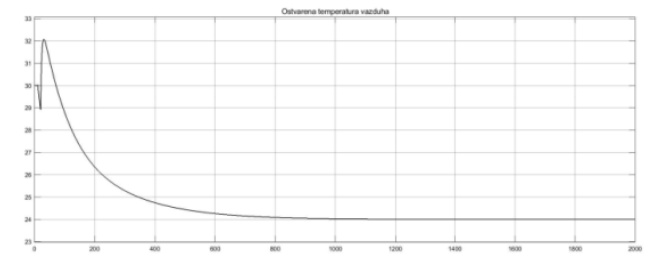

Slika 5. Izlazni signal KGH sistema, sugeno $3 \times 3$.

Performanse odziva prikazane su u tabeli 5.

Tabela 5. Performanse odziva KGH sistema, sugeno $3 \times 3$.

\begin{tabular}{|c|c|}
\hline Preskok [\%] & 33,6591 \\
\hline Vreme uspona [s] & 528,3194 \\
\hline Vreme smirenja [s] & 865,4929 \\
\hline Ess - Greška u ustaljenom stanju & $1,1320 \mathrm{e}-04$ \\
\hline
\end{tabular}

\subsection{Mamdani 5x5}

U ovom eksperimentu korišćen je mamdani $5 \times 5$ fuzzy regulator. Izlazni signal iz $\mathrm{KGH}$ sistema prikazan je na slici 6.

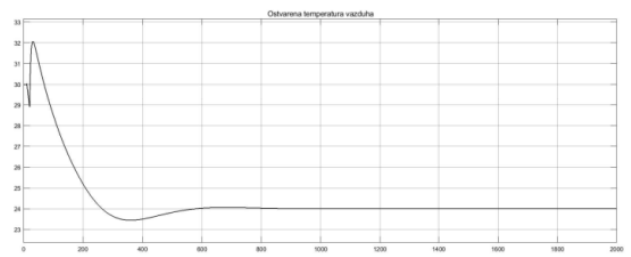

Slika 6. Izlazni signal KGH sistema, mamdani $5 \times 5$.
Performanse odziva prikazane su u tabeli 6 .

Tabela 6. Performanse odziva KGH sistema, mamdani $5 \times 5$.

\begin{tabular}{|c|c|}
\hline Preskok [\%] & 33,6407 \\
\hline Vreme uspona [s] & 270,9196 \\
\hline Vreme smirenja [s] & 649,8043 \\
\hline Ess - Greška u ustaljenom stanju & $1,0616 \mathrm{e}-05$ \\
\hline
\end{tabular}

\subsection{Sugeno $5 \times 5$}

$\mathrm{U}$ ovom eksperimentu korišćen je sugeno $5 \times 5$ fuzzy regulator. Izlazni signal iz KGH sistema prikazan je na slici 7

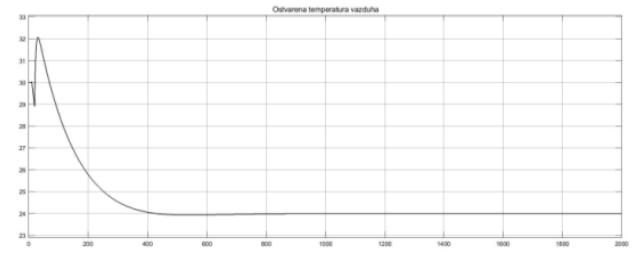

Slika 7. Izlazni signal KGH sistema, sugeno $5 \times 5$.

Performanse odziva prikazane su u tabeli 7.

Tabela 7. Performanse odziva KGH sistema, sugeno $5 \times 5$.

\begin{tabular}{|c|c|}
\hline Preskok [\%] & 33,6501 \\
\hline Vreme uspona [s] & 349,6044 \\
\hline Vreme smirenja [s] & 481,3783 \\
\hline Ess - Greška u ustaljenom stanju & $1,8336 \mathrm{e}-05$ \\
\hline
\end{tabular}

\subsection{Poređenje performansi odziva KGH sistema}

$\mathrm{Na}$ osnovu dobijenih rezultata, može se zaključiti da su regulatori $5 \times 5$, stabilniji od regulatora $3 \times 3$. Imaju kraće vreme uspona i vreme smirenja. Takođe, imaju manju grešku u ustaljenom stanju, dok im je preskok isti.

Pri poređenju regulatora po tipu, može se zaključiti da je mamdani $3 \times 3$ stabilniji od sugeno $3 \times 3$. Ima kraće vreme uspona i vreme smirenja. Takođe, ima manju grešku u ustaljenom stanju, dok im je preskok isti. Ali, kod tipa regulatora $5 \times 5$, sugeno ima značajno manje vreme smirenja, dok su mu vreme uspona i greška u ustaljenom stanju neznatno veće. Može se zaključiti da je sugeno $5 \times 5$ ipak stabilniji od mamdani $5 \times 5$.

\subsection{Optimizacija tabele pravila fuzzy regulatora pomoću GA}

Za optimizaciju tabele pravila pomoću GA odabran je mamdani 3x3. Urađena su dva eksperimenta, u cilju poređenja performansi. Razlikuju se samo u kriterijumu zaustavljanja. U prvom eksperimentu podešen je kriterijum zaustavljanja na deset generacija. Dok je u drugom eksperimentu podešen na dvadeset generacija.

\subsubsection{Mamdani 3x3 GA10}

Dobijena tabela pravila mamdani $3 \times 3$ fuzzy regulatora pomoću GA nakon deset generacija prikazana je u tabeli 8.

Tabela 8. Tabela pravila mamdani $3 \times 3-$ GA10.

\begin{tabular}{|c|c|c|c|}
\hline$e^{\Delta e}$ & $N$ & $Z$ & $P$ \\
\hline$N$ & $N S$ & $N B$ & $N S$ \\
\hline$Z$ & $P B$ & $Z$ & $N B$ \\
\hline$P$ & $Z$ & $P B$ & $N S$ \\
\hline
\end{tabular}

Izlazni signal iz KGH sistema prikazan je na slici 8 . 


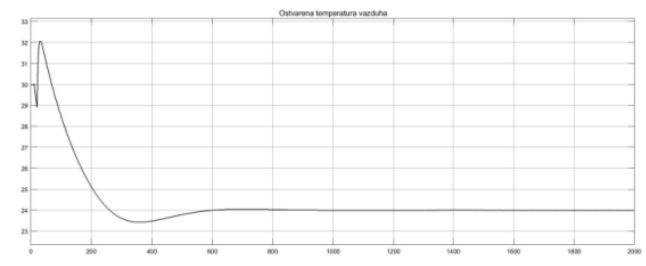

Slika 8. Izlazni signal KGH sistema, mamdani $3 \times 3-$ GA10.

Performanse odziva prikazane su u tabeli 9.

Tabela 9. Performanse odziva KGH sistema, mamdani $3 \times 3-$ GA10.

\begin{tabular}{|c|c|}
\hline Preskok [\%] & 33,6350 \\
\hline Vreme uspona [s] & 265,5720 \\
\hline Vreme smirenja [s] & 661,2735 \\
\hline Ess - Greška u ustaljenom stanju & $1,1209 \mathrm{e}-04$ \\
\hline
\end{tabular}

\subsubsection{Mamdani 3x3 GA20}

Dobijena tabela pravila mamdani $3 \times 3$ fuzzy regulatora pomoću GA nakon dvadeset generacija prikazana je $\mathrm{u}$ tabeli 10 .

Tabela 10. Tabela pravila mamdani $3 \times 3$ - GA20.

\begin{tabular}{|c|c|c|c|}
\hline$e^{\Delta e}$ & $N$ & $Z$ & $P$ \\
\hline$N$ & $N S$ & $N B$ & $Z$ \\
\hline$Z$ & $Z$ & $Z$ & $N S$ \\
\hline$P$ & $P S$ & $P B$ & $N B$ \\
\hline
\end{tabular}

Izlazni signal iz KGH sistema prikazan je na slici 9.

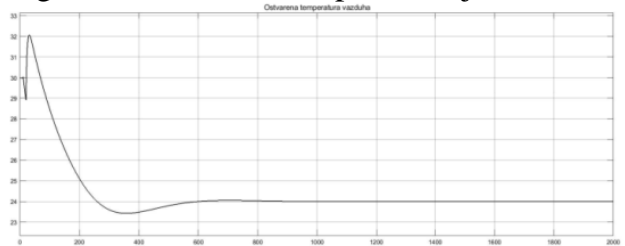

Slika 9. Izlazni signal KGH sistema, mamdani 3x3GA20.

Performanse odziva prikazane su u tabeli 11.

Tabela 11. Performanse odziva KGH sistema, mamdani $3 \times 3-G A 20$.

\begin{tabular}{|c|c|}
\hline Preskok [\%] & 33,6383 \\
\hline Vreme uspona [s] & 262,0181 \\
\hline Vreme smirenja [s] & 657,4461 \\
\hline Ess - Greška u ustaljenom stanju & $2,3334 \mathrm{e}-04$ \\
\hline
\end{tabular}

\subsubsection{Poređenje performansi odziva KGH sistema nakon optimizacije tabele pravila}

$\mathrm{Na}$ osnovu dobijenih rezultata iz prvog eksperimenta, može se zaključiti da je regulator nakon deset generacija stabilniji od onog pre optimizacije. Vreme uspona i vreme smirenja mu je manje. Greška u ustaljenom stanju je veća. Dok im je preskok isti.

$\mathrm{Na}$ osnovu dobijenih rezultata iz drugog eksperimenta, može se zaključiti da je regulator nakon dvadeset generacija još stabilniji u odnosu na regulator nakon deset generacija. Vreme uspona i vreme smirenja mu je manje. Greška u ustaljenom stanju je veća, dok im je preskok isti.

\section{ZAKLJUČAK}

Regulacija temperature zasnovana na PI-like fuzzy regulatorima i GA razvijena je da bi se optimizovala regulacija temperature KGH sistema. Projektovano je više različitih regulatora kako bi se uporedile performanse odziva i izabrao najefikasniji za upravljanje simulacionim modelom KGH sistema.

Optimizacijom tabele pravila PI-like fuzzy regulatora pomoću GA su dobijene još bolje performanse odziva KGH sistema.

$\mathrm{Na}$ osnovu dobijenih rezultata može se doći do zaključka da postoji mogućnost uštede električne energije, jer se upotrebom PI-like fuzzy regulatora i GA povećava energetska efikasnost sistema. Može se istaći da je ovakav način upravljanja KGH sistemima izuzetno pogodan $\mathrm{i}$ finansijski isplativ i da ima smisla razmišljati o upotrebi ovakvih regulatora kada se želi ostvariti optimalno upravljanje KGH sistemima.

\section{LITERATURA}

[1] Afram, F. Janabi-Sharifi: ,Theory and applications of HVAC control systems - A review of model predictive control (MPC)“", Building and Environment 72 (2014), pages 343-355

[2] Z. Živković, M. Vasić, A. Kuzmanović: „Predlog mera za finansiranje energetske efikasnosti u zgradarstvu u Srbiji“, Građevinska knjiga, Beograd, 2011

[3] Shaimaa Seyam (November 5th 2018). Types of HVAC Systems, HVAC System, Mohsen Sheikholeslami Kandelousi, IntechOpen

[4] I. Micić: „Fazi sistemi“, Prirodno-matematički fakultet, Univerzitet u Nišu, 2015

[5] F. Kulić: „Inteligentni upravljački sistemi“, Fakultet tehničkih nauka, Univerztitet u Novom Sadu, 2014

[6] S. Turajlić: „Osnovni principi Fazi upravljanja procesima“, Elektrotehnički fakultet, Univerzitet u Beogradu, 2014

[7] M. Anderson, M. Buehner, P. Young, D. Hittle, C. Anderson, J. Tu, D. Hodgson: „An experimental system for advanced heating, ventilating and air conditioning (HVAC) control", Energy and Buildings 39 (2007) 136-147

\section{Kratka biografija:}

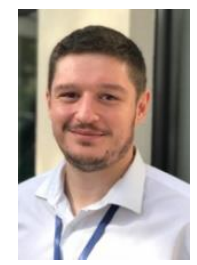

Saša Maksimović rođen je 30.06.1989. godine u Šapcu. 2008. godine upisuje Fakultet tehničkih nauka, univerziteta u Novom Sadu, oblast: Elektrotehnika i računarstvo, studijski program: Računarstvo i automatika, usmerenje: Automatika i upravljanje sistemima. Osnovne akademske studije završava 2013. godine i nastavlja sa obrazovanjem upisom na master akademske studije istog usmerenja. 